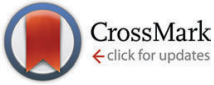

Cite this: Chem. Commun., 2015, 51,9046

Received 24th February 2015, Accepted 22nd April 2015

DOI: $10.1039 / \mathrm{c5cc01654a}$

www.rsc.org/chemcomm

\section{One-step synthesis of a cyclic 2,17-dioxo[3,3](4,4') biphenylophane and first preparation of a microporous polymer network from a macrocyclic precursor by cyclotrimerization $\dagger$}

\author{
Suman Kalyan Samanta, ${ }^{\text {a }}$ Eduard Preis, ${ }^{a}$ Christian W. Lehmann, ${ }^{\mathrm{b}}$ Richard Goddard, ${ }^{\mathrm{b}}$ \\ Saientan Bag, ${ }^{C}$ Prabal K. Maiti, ${ }^{c}$ Gunther Brunklaus ${ }^{d}$ and Ullrich Scherf ${ }^{a}$
}

One-step synthesis of a cyclic 2,17-dioxo[3,3](4,4')biphenylophane (MC) was achieved in high yield; its structure was verified by single crystal X-ray analysis. As a first example, a microporous polymer network was formed from macrocycle $\mathrm{MC}$ via acid-catalysed cyclotrimerization yielding a BET surface area of ca. $570 \mathrm{~m}^{2} \mathrm{~g}^{-1}$.

Microporous polymer networks (MPNs) are fully organic, covalently crosslinked, porous architectures that are attractive due to their high surface areas. ${ }^{1}$ Such MPNs can be prepared under affordable, transition-metal-free conditions. ${ }^{2}$ MPNs often possess functional groups such as extended $\pi$-conjugated segments and coordinating sites that make these networks attractive candidates for specialized fields of application, such as energy transfer/storage, gas storage/ gas separation or heterogeneous catalysis. ${ }^{3}$ Therefore, research into MPNs is challenging, especially towards novel advanced materials that combine microporosity with other useful functions.

Up to now, the highest specific surface area for a MPN, as determined by the Brunauer-Emmett-Teller (BET) method, has been $5640 \mathrm{~m}^{2} \mathrm{~g}^{-1}$, which was achieved for a polymer network obtained by Qiu, Zhu et al. from Ni(0)-mediated Yamamoto coupling of tetra(4-bromo-phenyl)methane. ${ }^{4}$ Thomas et al. reported cyclotrimerization of aromatic dinitriles under ionothermal conditions (molten zinc chloride at high temperature), producing triazine-based covalent polymer frameworks with BET surface areas $\left(S_{\mathrm{BET}}\right)$ of up to $2475 \mathrm{~m}^{2} \mathrm{~g}^{-1} \cdot{ }^{5}$ Côté, Yaghi et al. reported cyclotrimerization of diboronic acids leading to the formation of

\footnotetext{
${ }^{a}$ Macromolecular Chemistry Group and Institute for Polymer Technology,

Wuppertal University, Gauss-Strasse 20, 42119 Wuppertal, Germany.

E-mail: sksiisc@gmail.com, scherf@uni-wuppertal.de

${ }^{b}$ Max-Planck-Institut für Kohlenforschung, Kaiser-Wilhelm-Platz 1,

45470 Mülheim an der Ruhr, Germany

${ }^{c}$ Center for Condensed Matter Theory, Department of Physics,

Indian Institute of Science, Bangalore 560 012, India

${ }^{d}$ Westfälische Wilhelms-Universität, Institut für Physikalische Chemie,

Corrensstr. 28/30, 48149 Münster, Germany

$\dagger$ Electronic supplementary information (ESI) available: Experimental section, supporting figures and tables and also the single crystal X-ray structure analysis of MC. CCDC 1050402. For ESI and crystallographic data in CIF or other electronic format see DOI: 10.1039/c5cc01654a
}

boroxine-based crystalline covalent frameworks with $S_{\mathrm{BET}}$ values up to $1590 \mathrm{~m}^{2} \mathrm{~g}^{-1} .^{6}$ Recently, cyclotrimerization of bifunctional diketo-s-indacene derivatives was successfully achieved. ${ }^{7}$ The resulting products yielded BET surface areas of up to $1650 \mathrm{~m}^{2} \mathrm{~g}^{-1}$ under metal free conditions (using methane sulfonic acid as a condensing agent) compared to $1165 \mathrm{~m}^{2} \mathrm{~g}^{-1}$ in the case of condensation with $\mathrm{TiCl}_{4}$ as Lewis acid. Kaskel et al. reported a related acid-catalyzed cyclotrimerization of bifunctional acetyl derivatives forming MPNs with $S_{\mathrm{BET}}$ values of $895 \mathrm{~m}^{2} \mathrm{~g}^{-1}$ (using $\mathrm{SiCl}_{4}$ ) and $832 \mathrm{~m}^{2} \mathrm{~g}^{-1}$ (using $p$-toluene sulfonic acid). ${ }^{8}$ Notably, a rather high $S_{\mathrm{BET}}$ value of up to $2250 \mathrm{~m}^{2} \mathrm{~g}^{-1}$ was obtained for microporous polymer networks prepared using a metal-free poly-hydroxymethylation procedure which is among the highest values observed for this class of MPNs. ${ }^{9}$ In this report, we for the first time use a macrocycle (Scheme 1) as a building block for the design of microporous polymer networks via the acidcatalysed cyclotrimerization protocol. Another example for the

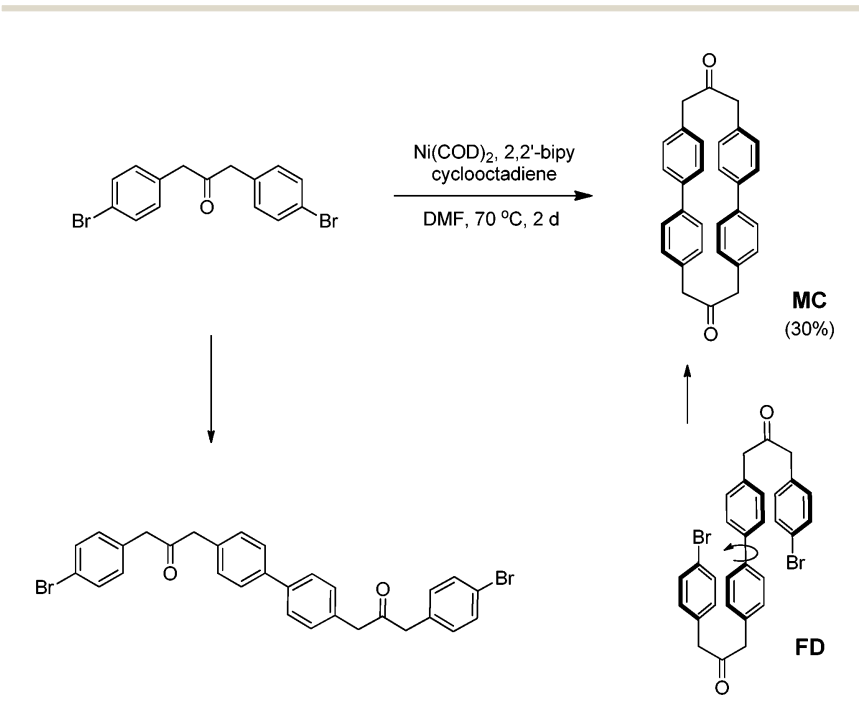

Scheme 1 One-step synthesis of the cyclic 2,17-dioxo[3,3](4,4') biphenylophane (MC), including a favourable, folded conformation of the monocoupled, dimeric intermediate for ring closure. 
incorporation of macrocyclic precursors into an organic cage framework (OCF) following a so-called "cage-to-framework" approach was published recently. ${ }^{10}$ In a related research area supramolecular polymerization of metallacyclic precursors has been described. ${ }^{11}$ In addition, supramolecular organic frameworks ${ }^{12}$ as well as metal organic frameworks ${ }^{13}$ containing macrocyclic building blocks were also developed. Our macrocyclic precursor was prepared using a simple one-step procedure via dimerization of an aromatic di-bromo compound.

The synthesis of macrocycles from $\alpha, \omega$-difunctionalized precursors is generally challenging due to the competition between cyclic and linear chain products. Also, by maintaining high dilution conditions often low yields of cyclic products are obtained. However, if the macrocycles are prepared using a simple one-step, single-pot process, the achieved yields typically benefit over the multistep synthesis result, particularly in terms of the total reaction time. ${ }^{14}$ The amount of macrocycles formed is highly dependent on the conformation of the intermediate that is present after the first coupling step. Favourably, the intermediate adopts a conformation for which the intermolecular macrocyclization easily occurs. Herein, we describe the one-step synthesis of 2,17-dioxo[3,3](4,4')biphenylophane macrocycle (MC) using a two-fold, Ni(0)-mediated Yamamoto coupling procedure. The structure of the macrocycle was verified by single crystal X-ray analysis, while the conformation of the mono-coupled intermediate was investigated by theoretical calculations. The macrocycle was further used for the synthesis of a microporous polymer network, the first MPN that is based on a macrocyclic precursor, yielding a BET surface area of up to $570 \mathrm{~m}^{2} \mathrm{~g}^{-1}$.

Macrocycle MC was obtained in a single-step Yamamoto coupling as described in Scheme 1 (also see the Experimental section, ESI $\dagger$ ). Slow addition of the dibromo compound 1,3-bis(4-bromophenyl)-propan-2-one into the solution containing the $\mathrm{Ni}(0)$ reagent under high dilution conditions leads to the formation of the dimer along with linear, acyclic byproducts (Fig. S1, ESI $\dagger$ ). Although formation of the macrocycle is less favoured, a yield of $30 \%$ could be achieved in this instance. In a literature report, the same macrocycle was isolated in only $<1 \%$ yield in a multistep sequence. ${ }^{15}$

The presence of linear by-products indicates that the reaction takes place in a stepwise manner where a linear dimer is initially formed, which can adopt a variety of different conformations. Cyclisation is favoured for the folded conformation FD (Scheme 1) for which the two bromo end groups are prearranged for macrocyclization. Theoretical calculations were performed to predict the total energies of probable conformations of the linear dimer. Among the calculated geometries, two conformations ((i) and (ii), Fig. S2, ESI $\dagger$ ) with a folded structure possess lower energy when compared to a linear, non-folded arrangement. Somewhat different to FD, for the minimum energy conformation (i), one 4-bromobenzyl moiety is parallel to the axis of the biphenyl unit while the other 4-bromobenzyl group is arranged perpendicularly to the biphenyl axis perhaps to avoid steric repulsion and to reduce the dipole moment. Generally, however, linear conformations of the openchain dimer show higher energies (Table S1, ESI $\dagger$ ) thus indicating that folded conformations are preferred. Calculations of transition state geometry resulted in a conformation that is similar
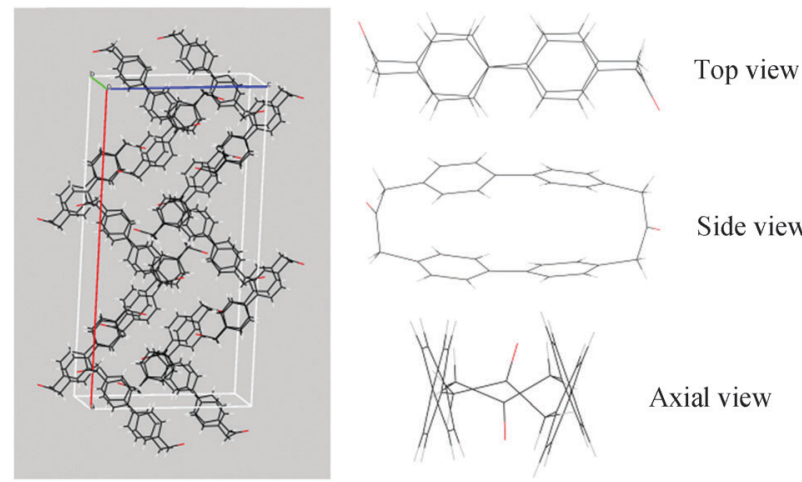

Fig. 1 Single crystal $X$-ray structure of macrocycle $M C$ including the geometry of the single molecules and packing in the unit cell.

to FD. Moreover, the optimized geometry of the macrocycle resembles the one extracted from a single crystal diffraction analysis (Fig. 1 and Fig. S3, ESI $\dagger$ ). Hereby, the crystal shows an anti-orientation of the two carbonyl moieties while theoretical calculations predict similar energies for both anti- or syn-oriented carbonyl groups. The crystal belongs to space group $C 2 / c$ with unit cell parameters $a=31.067(15) \AA, b=13.835(6) \AA$, and $c=15.670(7) \AA$, cell volume $V=6724(5) \AA^{3}$ and a monoclinic angle $\beta$ of 93.25(1) ${ }^{\circ}$. The long axes of the two biphenyl moieties are arranged parallel while the biphenyl dihedral angle is about $36^{\circ}$ and the through space $\pi-\pi$ stacking distance is $c a$. $3.5 \AA$ (see the ESI $\dagger$ for crystal structure analysis). In the UV-vis spectrum of $\mathbf{M C}$ we observed a slight, about $10 \mathrm{~nm}$ red-shift of the absorption maximum (260 nm) compared to biphenyl as a model compound, accompanied by a weak low energy shoulder at $c a .315 \mathrm{~nm}$, possibly reflecting ground state interactions of the two biphenyls (Fig. 2). ${ }^{16}$ Interestingly, the fluorescence maximum shows a noticeable $103 \mathrm{~nm}$ bathochromic shift for MC when compared to the isolated biphenyl chromophore, likely as a result of the formation of $\pi$-stacked aggregates. The fluorescence quantum efficiency of MC in dichloromethane was estimated to be $25 \%$ with respect to biphenyl as standard $\left(18 \%\right.$ in cyclohexane $\left.{ }^{17}\right)$.

Cyclotrimerization of either indan-1-one ${ }^{18}$ or indan-1,3-dione $e^{7,18 a, 19}$ in the formation of truxene cores can be accomplished by either protic (such as sulfuric acid, methanesulfonic acid (MSA),

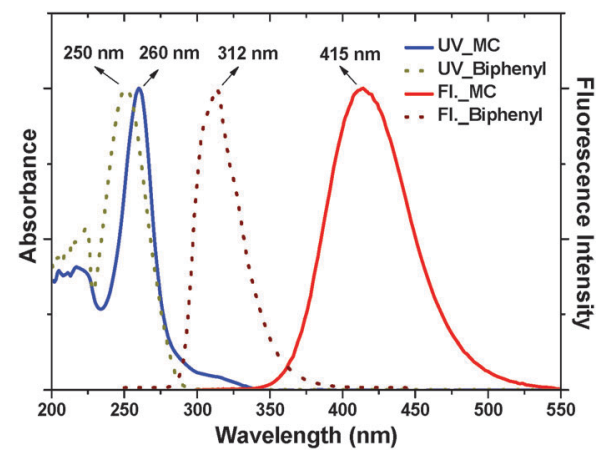

Fig. 2 Normalized UV-vis and fluorescence spectra of macrocycle MC and biphenyl (as a comparison) recorded in dichloromethane ( $\lambda_{\text {ext. }}: 245 \mathrm{~nm}$ for $\mathrm{MC}$ and $235 \mathrm{~nm}$ for biphenyl). 

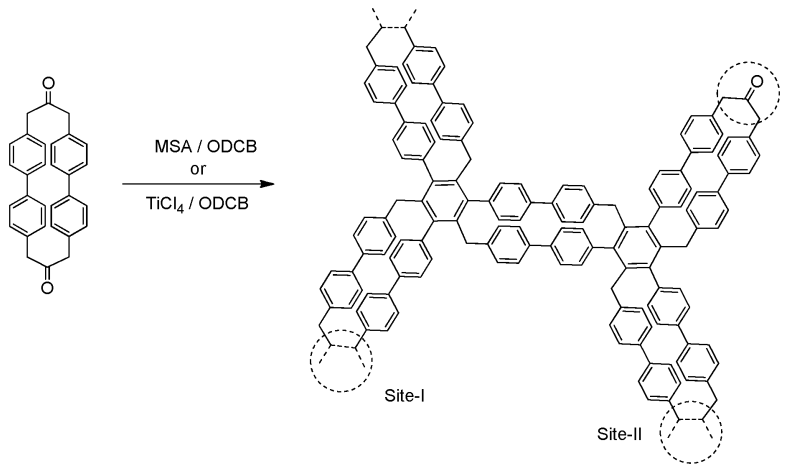

Scheme 2 Synthesis of microporous polymer network through acid catalyzed cyclotrimerization of macrocycle $\mathbf{M C}$ and an idealized structure of the resulting crosslinked polymer network.

p-toluenesulfonic acid, polyphosphoric acid etc.) or Lewis acids (such as titanium tetrachloride $\left(\mathrm{TiCl}_{4}\right)$, boron tribromide, molten zinc chloride etc.). Using such a protocol, the formation of microporous polymer networks (MPNs) was achieved from bifunctional $s$-indacene derivatives ${ }^{7}$ or bifunctional acetyl compounds ${ }^{8}$ with high specific BET surface areas. Considering these literature results, a cyclotrimerization reaction was also tested for our new macrocycle MC with protic acids (MSA) or Lewis acids $\left(\mathrm{TiCl}_{4}\right)$, respectively (Experimental section, ESI $\dagger$ ). Notably, dark colored rather insoluble products could be obtained in both cases.

Scheme 2 depicts the (idealized) structure of the resulting cross-linked polymer network. Within the network, the macrocyclic building blocks of the MPN can adopt an anti- (Site-II) or syn- (Site-I) structure regarding the $-\mathrm{CH}_{2}$ - links. With respect to the newly formed hexa-substituted benzene cores, a symmetric arrangement of the substituents is assumed, thus minimizing steric expulsion. The FT-IR spectrum of macrocycle MC exhibits a strong $\mathrm{C}=\mathrm{O}$ stretching band at $1690 \mathrm{~cm}^{-1}$. However, in the

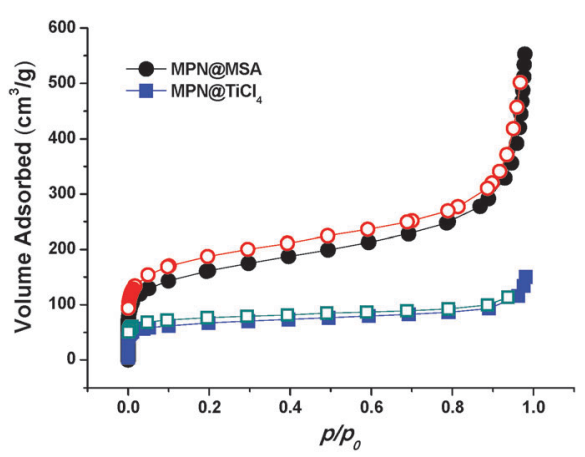

Fig. 3 BET nitrogen sorption isotherms for the microporous polymer networks (filled symbols represent adsorption and empty symbols represent desorption branches). polymer network the intensity of the band strongly decreases and is shifted to $1708 \mathrm{~cm}^{-1}$ (representing keto end-groups) along with a new band generated at $1600 \mathrm{~cm}^{-1}$ due to a $\mathrm{C}=\mathrm{C}$ stretching transition of the hexa-substituted benzene cores (Fig. S4, ESI $\dagger$ ). ${ }^{20}{ }^{13} \mathrm{C}\left\{{ }^{1} \mathrm{H}\right\}$ CPMAS NMR analysis of the MPNs confirmed the presence of aromatic units (100-160 ppm) and $-\mathrm{CH}_{2}$ - linkers (25-60 ppm). In addition a small fraction of keto terminal groups (170-210 ppm) is also present (Fig. S5, ESI $\dagger$ ). The MPNs obtained with either MSA or $\mathrm{TiCl}_{4}$ were thermally stable up to $200{ }^{\circ} \mathrm{C}$ (TGA, Fig. S6, ESI $\dagger$ ). Although, MC shows intrinsic fluorescence at $415 \mathrm{~nm}$ (Fig. 2), the resulting $\pi$-conjugated polymer networks did not exhibit any fluorescence.

The porosity of the polymeric products was measured by nitrogen sorption at $77 \mathrm{~K}$ and BET surface areas were extracted. The nitrogen adsorption and desorption isotherms presented in Fig. 3 indicate a type-I microporous material according to the IUPAC classification. The steep increase in the slope of the isotherm starting at $p / p_{0}=0.9$ indicates the presence of macropores probably caused by inter-particle voids. ${ }^{8}$ A BET surface area of $568 \mathrm{~m}^{2} \mathrm{~g}^{-1}$ was calculated for the polymer network obtained under metal-free conditions (using MSA), while a $S_{\mathrm{BET}}$ value of $245 \mathrm{~m}^{2} \mathrm{~g}^{-1}$ was achieved by condensation with $\mathrm{TiCl}_{4}$ accompanied by the total pore volumes of $0.85 \mathrm{~cm}^{3} \mathrm{~g}^{-1}$ and $0.23 \mathrm{~cm}^{3} \mathrm{~g}^{-1}$, respectively. Gas adsorption studies were performed with $\mathrm{H}_{2}, \mathrm{CO}_{2}$ and $\mathrm{CH}_{4}$ (Table 1 and Fig. S7, ESI $\dagger$ ) and in each case the amount of gas adsorbed is higher for the MPN generated under metal-free conditions. A lower BET surface area as well as lower gas adsorption values for the condensation product with $\mathrm{TiCl}_{4}$ could be due to the presence of catalyst traces that block a certain part of the micropores. Thus, TGA in air showed a residue of $26.6 \%$ for the $\mathrm{TiCl}_{4}$-condensation product at $950{ }^{\circ} \mathrm{C}$ compared to only $1.9 \%$ for the MSA-condensation product (Fig. S8, ESI $\dagger$ ).

In conclusion, the dimeric, biphenyl-based macrocycle MC was generated with a high yield of up to $30 \%$ in a simple onestep, Ni(0)-mediated Yamamoto coupling. The structure of the macrocycle was confirmed by single crystal analysis. Theoretical calculations point to a folded conformation of the acyclic dimer, thus supporting the formation of the macrocycle. Acidcatalysed cyclotrimerization was successfully applied for the condensation of MC into a microporous polymer network (MPN). The microporous network displays BET surface areas of up to $570 \mathrm{~m}^{2} \mathrm{~g}^{-1}$ for the product synthesized under metal-free acid conditions (with MSA).

SKS gratefully acknowledges the Alexander von Humboldt Foundation for a post-doctoral research fellowship. We acknowledge the Synchrotron Light Source ANKA (KIT, Karlsruhe) for provision of instruments at their beamlines and thank Dr Gernot Buth for his support at the SCD beamline.

Table 1 BET surface areas and the corresponding gas adsorption data for the MPNs generated with MSA and $\mathrm{TiCl}_{4}$

\begin{tabular}{lllll}
\hline & $\begin{array}{l}\text { Surface area } \\
\left(\mathrm{m}^{2} \mathrm{~g}^{-1}\right)\end{array}$ & $\begin{array}{l}\text { Total pore volume } \\
\left(\mathrm{cm}^{3} \mathrm{~g}^{-1}\right)\end{array}$ & $\begin{array}{l}\mathrm{H}_{2} \text { uptake } \\
\left(\mathrm{cm}^{3} \mathrm{~g}^{-1}, \mathrm{wt} \%\right)\end{array}$ & $\begin{array}{l}\mathrm{CO}_{2} \text { uptake } \\
\left(\mathrm{cm}^{3} \mathrm{~g}^{-1}, \mathrm{wt}^{2}\right)\end{array}$ \\
\hline MPN@MSA & 568 & 0.85 & $88(0.79)$ & $\begin{array}{l}\mathrm{CH}_{4} \text { uptake } \\
\left(\mathrm{cm}^{3} \mathrm{~g}^{-1}, \mathrm{wt}^{2}\right)\end{array}$ \\
MPN@ TiCl & 245 & 0.23 & $52(0.47)$ & $13.90)$ \\
$4(2.82)$
\end{tabular}




\section{Notes and references}

1 (a) R. Dawson, A. I. Cooper and D. J. Adams, Prog. Polym. Sci., 2012, 37, 530-563; (b) A. Thomas, Angew. Chem., Int. Ed., 2010, 49, 8328-8344; (c) D. S. Kundu, J. Schmidt, C. Bleschke, A. Thomas and S. Blechert, Angew. Chem., Int. Ed., 2012, 51, 5456-5459; (d) D. Wu, F. Xu, B. Sun, R. Fu, H. He and K. Matyjaszewski, Chem. Rev., 2012, 112, 3959-4015.

2 (a) J. Weber, M. Antonietti and A. Thomas, Macromolecules, 2007, 40, 1299-1304; (b) K. T. Jackson, M. G. Rabbani, T. E. Reich and H. M. El-Kaderi, Polym. Chem., 2011, 2, 2775-2777; (c) M. G. Schwab, B. Fassbender, H. W. Spiess, A. Thomas, X. Feng and K. Müllen, J. Am. Chem. Soc., 2009, 131, 7216-7217; (d) A. Laybourn, R. Dawson, R. Clowes, J. A. Iggo, A. I. Cooper, Y. Z. Khimyak and D. J. Adams, Polym. Chem., 2012, 3, 533-537; (e) Z. Wang, B. Zhang, H. Yu, L. Sun, C. Jiao and W. Liu, Chem. Commun., 2010, 46, 7730-7732; $(f)$ Y. Luo, B. Li, L. Liang and B. Tan, Chem. Commun., 2011, 47, 7704-7706.

3 (a) R. E. Morris and P. S. Wheatley, Angew. Chem., Int. Ed., 2008, 47, 4966-4981; (b) Y. Zhang and S. N. Riduan, Chem. Soc. Rev., 2012, 41, 2083-2094; (c) Y. Kou, Y. Xu, Z. Guo and D. Jiang, Angew. Chem., Int. $E d ., 2011,50,8753-8757$; (d) N. B. McKeown and P. M. Budd, Chem. Soc. Rev., 2006, 35, 675-683; (e) G. Zhang, O. Presly, F. White, I. M. Oppel and M. Mastalerz, Angew. Chem., Int. Ed., 2014, 53, 1516-1520; $(f)$ A. Patra, J.-M. Koenen and U. Scherf, Chem. Commun., 2011, 47, 9612-9614; $(g)$ Z.-S. Wu, Y. Sun, Y.-Z. Tan, S. Yang, X. Feng and K. Müllen, J. Am. Chem. Soc., 2012, 134, 19532-19535.

4 T. Ben, H. Ren, S. Ma, D. Cao, J. Lan, X. Jing, W. Wang, J. Xu, F. Deng, J. M. Simmons, S. Qiu and G. Zhu, Angew. Chem., Int. Ed., 2009, 48, 9457-9460.

5 P. Kuhn, M. Antonietti and A. Thomas, Angew. Chem., Int. Ed., 2008, 47, 3450-3453.

6 A. P. Côté, A. I. Benin, N. W. Ockwig, M. O'Keeffe, A. J. Matzger and O. M. Yaghi, Science, 2005, 310, 1166-1170.

7 R. S. Sprick, A. Thomas and U. Scherf, Polym. Chem., 2010, 1, 283-285.
8 M. Rose, N. Klein, I. Senkovska, C. Schrage, P. Wollmann, W. Bohlmann, B. Bohringer, S. Fichtner and S. Kaskel, J. Mater. Chem., 2011, 21, 711-716.

9 E. Preis, C. Widling, G. Brunklaus, J. Schmidt, A. Thomas and U. Scherf, ACS Macro Lett., 2013, 2, 380-383.

10 Y. Jin, B. A. Voss, R. McCaffrey, C. T. Baggett, R. D. Noble and W. Zhang, Chem. Sci., 2012, 3, 874-877.

11 (a) X. Yan, S. Li, J. B. Pollock, T. R. Cook, J. Chen, Y. Zhang, X. Ji, Y. Yu, F. Huang and P. J. Stang, Proc. Natl. Acad. Sci. U. S. A., 2013, 110, 15585-15590; (b) X. Yan, T. R. Cook, J. B. Pollock, P. Wei, Y. Zhang, Y. Yu, F. Huang and P. J. Stang, J. Am. Chem. Soc., 2014, 136, 4460-4463.

12 L.-L. Tan, H. Li, Y. Tao, S. X.-A. Zhang, B. Wang and Y.-W. Yang, Adv. Mater., 2014, 26, 7027-7031.

13 L.-L. Tan, H. Li, Y.-C. Qiu, D.-X. Chen, X. Wang, R.-Y. Pan, Y. Wang, S. X.-A. Zhang, B. Wang and Y.-W. Yang, Chem. Sci., 2015, 6, 1640-1644.

14 C. Storz, M. Badoux, C. M. Hauke, T. Šolomek, A. Kühnle, T. Bally and A. F. M. Kilbinger, J. Am. Chem. Soc., 2014, 136, 12832-12835.

15 M. Yamaji, T. Tsukada, H. Shizuka and J. Nishimura, Chem. Phys. Lett., 2008, 460, 474-477.

16 H. A. Staab and M. Haenel, Chem. Ber., 1973, 106, 2190-2202.

17 I. B. Berlman, Handbook of fluorescence spectra of aromatic molecules, Academic Press, New York, 1971.

18 (a) E. V. Dehmlow and T. Kelle, Synth. Commun., 1997, 27, 2021-2031; (b) T. W. Warmerdam, R. J. M. Nolte, W. Drenth, J. C. Van Miltenburg, D. Frenkel and R. J. J. Zijlstra, Liq. Cryst., 1988, 3, 1087-1104; (c) A. W. Amick and L. T. Scott, J. Org. Chem., 2007, 72, 3412-3418; (d) B. Gómez-Lor, Ó. de Frutos, P. A. Ceballos, T. Granier and A. M. Echavarren, Eur. J. Org. Chem., 2001, 2107-2114.

19 L. Sanguinet, J. C. Williams, Z. Yang, R. J. Twieg, G. Mao, K. D. Singer, G. Wiggers and R. G. Petschek, Chem. Mater., 2006, 18, 4259-4269.

20 K. Zhang, B. Tieke, F. Vilela and P. J. Skabara, Macromol. Rapid Commun., 2011, 32, 825-830. 